\title{
A Survey Data Archive Network in Africa - Possibilities and Practicalities
}

The Role of Survey Data Archives Survey Data Archives perform the dual functions of facilitating data sharing and assisting in safeguarding the quality of the data shared. Dedicated archives for the sharing of social survey data evolved as a result of the development of quantitative research within the social sciences, involving the collection of social statistics through surveys. Quantitative social research and the establishment of Survey Data Archives to house and disseminate the output of this research were in turn aided by the invention of the computer and its increasingly sophisticated technologies.

These two roles, safeguarding data quality and enabling data sharing, including providing training in survey research and data analysis, are integral to the work of Survey Data Archives. Worldwide, Survey Data Archives extend the work of national statistical agencies through these functions. A network of Survey Data Archives in Asia, Australasia, Western and Eastern Europe and North America, facilitates research cooperation and data sharing on a regional and global scale. This is not the case in Africa. However, Survey Data Archives may be the most appropriate facilities for ensuring the survival and usage of survey data in Africa, and an African Survey Data Archive network could optimize technological developments for the provision of access to African survey data. This article looks at the possibility of establishing such a Survey Data Archive network in Africa, advantages that would accrue from this, and obstacles to such a development.

The Value of Data Sharing for Policy Formulation Findings in data archiving literature confirm the importance of social survey data as a policy tool for social and economic development ${ }^{1}$. The data from these studies provides vital information on the state of nations. Government agencies now rely on social statistics generated by surveys conducted by state and private institutions as a basis for policy formulation, particularly related to economic growth and poverty alleviation. Survey Data Archives, which began as storage facilities for survey datasets, have gradually taken on a more active role in reprocessing and disseminating these data in the interests of research and policy-making.

The value of the Survey Data Archive's role as curator of quantitative national data in Africa cannot be overestimated, as much African survey research is lost to posterity through lack of data management and preservation structures for data products ${ }^{2}$. Economic and social development in African countries is linked to their ability to promote applied research. Governments need to be aware of the utility of information and their inability to act effectively without it. These countries may be left behind in the knowledge economy if they are unable to tap into global knowledge using modern technology, generate indigenous knowledge and disseminate this knowledge to ensure its practical use $\mathrm{e}^{3}$.

The establishment of national Survey Data Archives in African countries can be seen as part of the infrastructure enabling these countries to utilize knowledge that is produced locally and through international survey research. Survey Data Archives in Africa could act as intermediaries for data sharing from private and official survey research, and ensure the survival and quality of African survey data for re-use ${ }^{4}$. Failure to support secondary usage of survey data in Africa could mean this resource will be underused, and opportunities for national growth and for improving the quality of the survey research process through reexamination of data will be $\operatorname{lost}^{5}$.

\section{Data Archives and Data Quality in Africa}

As the value of survey data is realised, demands are concurrently being made to ensure the high quality of survey products on which development policies are based. Government agencies, academic institutions and the private sector have come to expect optimal usage of survey data, particularly in relation to the relevance, consistency and comparability of survey datasets. Here again, Survey Data Archives have a role to play. For example, the DataFirst archive in South Africa has begun to provide a valueadded service with regard to national statistical data, connecting the national statistical agency with data users, such as academics and government policy-makers. This archive provides feedback to Statistics South Africa on the relevance and usability of its datasets, and notifies data users on problems with and changes to national datasets ${ }^{6}$.

Data Sharing Organisations in Africa

In Africa, national statistical agencies have limited financial 
and staff resources for survey administration and analysis to feed into national policy. Consequently they do not actively share the microdata from their surveys. However, with the growing recognition that statistical data is an important national resource for scientific investigation and sound national decision-making, international organisations such as the World Bank, the United Nations and the International Monetary Fund, have initiated programs to stimulate production of African national statistics and their usage to formulate national policies. These have included the World Bank's African Household Survey Capability Programme in 1973 and the Addis Ababa Plan of Action for Statistical Development in Africa (AAPA) in the $1990 \mathrm{~s}^{7}$. The World Bank funds the International Household Survey Network, launched in 2004 to promote survey research in developing countries ${ }^{8}$. The UN initiated African Symposium on Statistical Development (ASSD), was convened in 2006 as a platform for the exchange of information on statistics and technical assistance with the collection and dissemination of African census data. At this symposium, delegates pledged to promote "knowledge management in statistics" on the continent ${ }^{9}$. In 2007, Africa's national statistics agencies, in collaboration with the UN Economic Commission for Africa and the African Development Bank, recommended a Draft Charter on Statistics for the continent, acknowledging the vital role quantitative data plays in development on the continent ${ }^{10}$.

Support for national statistical agencies on the continent is vital. However, establishment of a network of Survey Data Archives in Africa would be a complementary development, ensuring independent quality-monitoring of national datasets, and national and regional data sharing. In Africa, three Survey Data Archives have been established for these purposes. Two of these are in South Africa - the South African Data Archive (SADA), and DataFirst, an archive at the University of Cape Town. SADA is a government repository, which was established in 1993 with the assistance of consultants from the Danish Data Archive ${ }^{11}$, and is now part of the National Research Foundation. DataFirst is a grant-receiving initiative with the dual roles of facilitating data sharing for research, and training students in quantitative analysis of survey data. A third nascent Survey Data Archive has been established within the Ethiopia Central Statistical Agency ${ }^{12}$.

A development towards establishing Data Archives in other African countries, and possibly facilitating linkages among them, occurred at the 2007 Conference of the International Association for Social Science Information Service and Technology (IASSIST). Delegates from Africa and those interested in data management in Africa met and decided to create an electronic mailing list for sharing ideas. Members of this group included staff from DataFirst (South Africa) and representatives from Statistical Agencies in Cameroon, Ethiopia, the Gambia, Ghana, Mozambique, Niger and Uganda (the listserve address is iassist-africa@lists.carleton.edu). Group activities thus far involve exchanging ideas on data management in Africa, and discussions regarding collaboration on staff training.

\section{The Demand for Data in Africa}

Developments towards the establishment of Survey Data Archives in Africa reflect an increasing regional demand for high-quality statistics on which to base social and economic policy. However, it is difficult to quantify this demand to support the value of establishing data management organisations in the region.

Examination of statistics maintained by Survey Data Archives in some countries can indicate the demand for secondary data ${ }^{13}$. These include statistics of requests for data, derived from online data usage forms, and records of dataset preparation and distribution. Additionally, one can judge the extent of usage of shared data by assessing the number of documents produced from the holdings of national Survey Data Archives. Many Survey Data Archives have web-based bibliographies of publications that are based on their survey data. From these we can ascertain at least the quantity of works produced with shared data. However, frequency counts cannot measure the quality of the academic output from secondary data use $^{14}$.

Systematic statistics on secondary use of survey data in Africa have not been compiled. As the South African Data Archive (SADA) does not publish statistics of dataset distribution, judging demand for datasets in their collection is hindered. However, one significant case in South Africa demonstrates the value academics and policymakers find in re-using South African survey data. The South African Living Standards Measurement Survey (LSMS) was conducted in South Africa by the World Bank and the University of Cape Town. This was the first household survey conducted in South Africa, with the final dataset released in 1995. The data have been heavily used since its release, both for academic and teaching purposes. Many of the reports emanating from secondary analysis of the data from this survey have been used in policy-making ${ }^{15}$.

By January 2007, the South African LSMS data had spawned 78 monographs and 39 journal articles, by international and local academics, published in South Africa and abroad. Forty-six unpublished papers were produced using the data. These publications represent work commissioned by government bodies and international funding agencies, readers for academic courses, and publications for local and international journals and conferences. In addition, the dataset is used pedagogically; for example as part of an annual course on survey analysis at the University of Cape Town ${ }^{16}$. 


\section{Obstacles to the Establishment of a Survey Data Archive Network in Africa}

The lack of country infrastructures for establishing facilities for data archiving and regional data sharing is a significant obstacle to the development of a Survey Data Archive network in Africa ${ }^{17}$. A further obstacle is the lack of an educated and skilled workforce to appreciate the advantages of global and indigenous information and to utilise new technologies to access this information. Thus, in Africa there has been poor archiving of survey microdata, resulting in the loss of valuable data in many countries. The current situation in Africa is that the results of African social surveys and censuses are often archived outside the continent. These data are archived and disseminated either by foreign research organizations conducting survey research in Africa or by international organizations funding development projects in the region.

\section{Historical Obstacles}

Obstacles to effective survey data management in Africa mirror those experienced by the newly established Survey Data Archives in Eastern Europe. These problems include the lack of a data-sharing culture, making regional cooperation in survey research difficult ${ }^{18}$. Historical animosity between African governments and academia has hampered the use of applied research for policy development. Early on African academics saw the value of research for economic development. In 1981, the Southern African Development Research Association (SADRA) emphasised that

"...research in the region [should] provide a necessary base for the policy choices governments must make to promote development ${ }^{19}$ ",

However, the attitude of many government officials remains uncooperative; even basic statistical data collected by governments, such as census information, has not been easily available to researchers ${ }^{20}$. African academics have also advocated regional cooperation in Africa for research and dissemination of results, given the scarce resources in the region ${ }^{21}$. Historically, however, Many African governments and research bodies have maintained relationships primarily with their colonizing powers, rather than attempting to forge regional ties ${ }^{22}$.

Data sharing is mutually beneficial for government statisticians and the academic community, both regionally and nationally. The public must perceive academic research based on national survey data as an extension and enhancement of official statistical information. This will increase their trust in the official data and in the national agencies responsible for its compilation. Academic research and policy formation will benefit through the process official data-collection ${ }^{23}$. Networked Survey Data Archives could facilitate this to aid national and regional development in Africa.

\section{Lack of Resources}

Here also, the situation in Africa reflects the problems of data sharing in Eastern Europe. Funding for the establishment and upkeep of Survey Data Archives is meagre in both Africa and Eastern Europe, and there is a paucity of skilled staff to manage data archives. In contrast to Eastern Europe, in Africa the situation is further exacerbated by comparatively low levels of education among the general population, with the resultant lack of a critical mass of researchers to promote data sharing ${ }^{24}$. This deficiency also means African researchers are unable take advantage of the new information and communications technology for development ${ }^{25}$. This includes a paucity of skilled personnel to manage any technology infrastructure. Government policy-makers on the continent are also unskilled in using survey and census results ${ }^{26}$.

\section{Technical and Logistical Obstacles}

Difficulties also arise in the identification and location of suitable data for secondary analysis, as information about survey data in Africa may not be readily available to researchers. Technological infrastructure is needed to facilitate the archiving and sharing of research data in African countries. Internet access is limited, and internet users are few; Africans comprise just three percent of internet users worldwide ${ }^{27}$. This is partially due to a low level of internet research skills among African researchers. However this is exacerbated by the cost of accessing information in these countries, which is often higher than in the rest of the world.

Government regulatory mechanisms for telecommunications often make access to internet resources expensive and inefficient. Computer equipment is usually more expensive in Africa than in countries of the developed world $^{28}$. To compound this problem African countries often have bandwidth problems ${ }^{29}$. Furthermore, African countries need a reliable electricity source upon which internet infrastructures depend, and this is not always available.

Even where internet access is available, information on African surveys is scarce. A search of websites of African statistical agencies revealed that none of these national agencies provide a comprehensive list of the surveys and censuses they conduct. Requests for a list of surveys are met by referrals to online catalogues of publications. It would seem that these organizations are still in the pre-technology mode concerning data products. That is, planning for budgets and training tends to focus on sound methods of data collection and analysis, but does not support data sharing. In these statistical agencies, the end product of national censuses and sample surveys is envisioned (and presented to the public) as a series of reports on the findings. The production of microdata files from survey research to enable local and international researchers to conduct secondary analysis is not an integral part of the process. In South Africa, the national statistical 
agency does not publish a list of their surveys on their website. However, online analysis of some of their surveys is now possible through their NESSTAR server. The Survey Data Archives in South Africa provide information on South African survey datasets, and both SADA and DataFirst post their dataset holdings on their websites ${ }^{30}$.

Data producers in Africa are not yet harnessing new technologies in the interest of data sharing for development. However, these organisations may benefit from entering the information technology revolution at a late stage. Decreasing computer and communication costs allow "technology leapfrogging" in these countries, because they do not have to bear the costs of technology development and experimentation. Rather, these countries can begin to participate in a computer and telecommunication market with versatile and less expensive products for data sharing ${ }^{31}$. Any Survey Data Archives established in the region can also benefit from developments in data management worldwide.

\section{Language Issues}

Language is another barrier to identifying and sharing African datasets. Any regional coordination in data sharing in Africa must account for language difficulties. Unlike the countries of Latin America, which have Spanish as a common language (except Brazil and some parts of the West Indies), Africa has three languages for the purpose of research - English, French and Portuguese. Arabic is also spoken in some African countries. Ideally, this and the major regional languages should be considered in providing access to African data catalogues.

A possible solution to these logistical problems could be the creation of an Africa-wide data portal such as the one developed by the Multilingual Access to Data Infrastructures of the European Research Area (MADIERA) Project. The aim of this European Commission-funded project is to develop the European Social Science research infrastructure for data, and these efforts launched the MADIERA Portal in 2006. This portal is a multilingual front-end access to the data holdings of thirteen social science Survey Data Archives in Europe, which the researcher may use in any of nine languages ${ }^{32}$. The creation of an African data portal would necessitate an audit of existing African datasets to provide information on these for the portal, and links to the relevant data suppliers. This could be one of the first tasks of a Survey Data Archive network established on the continent.

\section{Data Ownership Issues in Africa}

Other barriers to sharing survey data through an African Survey Data Archive network include the dissuading motivations inherent in academia. This is not unique to African research, but is particularly relevant here because much of the survey work conducted in Africa is undertaken or at least co-produced by foreign organisations. Principal
Investigators from these organisations wish to have exclusive access to data to maximise their academic advantage. They consider themselves "owners" of the final data product. Because much of this survey data is in the private domain, no institutional or peer pressure exists to expand data availability.

Foreign researchers conducting surveys in Africa have little interest in devoting resources to preparing datasets for the benefit of academic competitors. Thus, they maintain exclusive rights to data collected in Africa, at least for extensive embargo periods. This often results in the survey microdata from these studies being unavailable to researchers in these African countries. For example, the Afrobarometer Project has used their superior funding and technical resources to harvest data from African countries, but does not place this data in the public domain for at least two years. African researchers not involved in the project are unable to utilise this data for research and policy development during the embargo period ${ }^{33}$.

In Africa, networks of Survey Data Archives could counter the dissuading factors inherent in the academic reward system. In South Africa, SADA and DataFirst have assisted in bringing the issue of data sharing to the attention of funding agencies, and have received funding support because of their perceived nature as valuable resources for academic advancement, as repositories of empirical information for development, and for their role in promoting scarce quantitative skills in developing countries $^{34}$. Hopefully, African funding agencies will in the future require, through research grant stipulations, that grantees prepare their data for secondary use and release it in a timely manner. This positive trend is occurring in some countries outside of Africa, facilitated by their respective Survey Data Archives ${ }^{35}$.

\section{Confidentiality Issues}

Protection of confidential data is one of the fundamental principals espoused by government statistical agencies, internationally and in Africa, as a necessary condition to ensure the trust of respondents, and therefore the accuracy and reliability of data collected ${ }^{36}$. Other organisations conducting surveys are also obligated to adhere to these principles. However, African researchers are increasingly requesting access to unit records from official surveys, and sharing records could compromise respondent confidentiality. These records offer great value to researchers needing empirical information. An important recent finding regarding statistical data is that a truly accurate picture of the national economy of a country cannot be obtained from analysis of only aggregate data ${ }^{37}$. Thus, access to unit records becomes important for research that impacts government policy. Other research needs call for a compromise between data access and data protection, for example, when information that links responses to individuals is needed for secondary analysis, as with 
epidemiological or panel studies ${ }^{38}$. Restrictions on the use of these linkages can hamper research.

As formal structures for data sharing, Survey Data Archives are able to support methods of protecting the confidentiality of respondent information. Archive staff can accomplish this by assisting in making the datasets anonymous. They can also facilitate wider usage of restricted access datasets by providing secure facilities for use by researchers, as in some parts of the world ${ }^{39}$. Thus they can play an important role in mitigating the confidentiality concerns of principal investigators and government statistical agencies in Africa.

Africa-wide comparative research is possible using linked datasets from different countries, such as the Demographic and Health data collected for the MeasureDHS Project. However, ensuring data confidentiality is compounded in comparative and cross-national research. Issues of regional concern in African research could be effectively handled by a continental network of Survey Data Archives. These networked archives could manage and monitor adherence to ethical principals in complex cross-national research, while standardizing data and access procedures ${ }^{40}$.

\section{Building on Existing Infrastructure}

Those interested in African Survey Data Archives must utilise existing structures, including current African networks, to provide the necessary resources for establishing a continental Survey Data Archive Network. Data exchange structures in Africa include government agencies and policy-making and regulatory bodies, intergovernmental scientific organizations, publicly-funded research institutions such as universities, publicly-funded data management institutions, such as data centres and libraries, and national and international $\mathrm{NGOs}^{41}$.

The wealthy institutions of higher education that support Survey Data Archives in North America are scarce on the African continent. However, African countries may be able to obtain funding from international grant agencies to support the development of Survey Data Archives. This assistance would be similar to the structures that support nascent Survey Data Archives in Eastern Europe $^{42}$. International funding agencies have been willing to support data sharing for improved research and governance in Africa, for example the World Bank's sponsoring of the development and use of their Microdata Management Toolkit for processing and distributing census microdata on the continent ${ }^{43}$. International funding has also directly enabled the establishment of the DataFirst Survey Data Archive in South Africa ${ }^{44}$. However, support from international funding agencies may not facilitate a coordinated effort towards data-sharing on the continent. The development of a continental network for sharing African social survey data could rather be facilitated by building on the existing government statistical agency structures, and promoting collaborative efforts among them. This could mean physically situating African Survey Data Archives within the government statistical offices, or as departments at African Universities.

In Western Europe and North America, most official statistical agencies play a supporting role for Data Archive Networks. Generally, they are one of the many suppliers of survey data to Survey Data Archives. In Africa, and in some countries in Eastern Europe, government statistics departments have a less clearly defined role for regional data sharing. They are historically the main producers and suppliers of survey information in countries with poorly developed research structures. For example, in Lithuania the main holder of empirical data is the Lithuanian Department of Statistics ${ }^{45}$. It may therefore be practical to establish Survey Data Archives as semi-autonomous units within Africa statistical agencies. Such developments are already underway in the region. One example is the Ethiopian Central Statistical Agency, where a Survey Data Archive has been established and is producing national micro-datasets for secondary analysis, using the World Bank's Microdata Management Toolkit ${ }^{46}$.

Establishing these archives in the National Statistical Agencies would allow these organizations to utilize their existing data management infrastructures, and could improve official data management practices when data users interact directly with national data suppliers and provide regular feedback. However, situating African Survey Data Archives in national statistical agencies would circumvent independent quality control of the data produced. Quality monitoring of datasets is a vital role played by Survey Data Archives. Thus any archive administered and funded by a national Statistical Agency would have its objectivity compromised.

These Survey Data Archives would need to collect all survey datasets available nationally, both publicly-funded and commercial, to properly fulfil the role of national Survey Data Archives. Statistics offices worldwide have traditionally only archived and disseminated their own survey datasets. They may be resistant to house datasets from independent surveys, or unprepared to promote secondary usage because they view them as inferior to their own survey products. Conversely, other data producers may be reluctant to deposit their datasets with a government organization, doubting their objectivity and ability to assign their data equal weight to potential data users. Another problem is that situating Survey Data Archives in a government department may lead to the perception among researchers that data produced has a government bias. This is particularly valid in an African context, with a history of intolerance between government and academia. This may restrict usage of datasets from archives established within national statistical agencies.

Establishing Survey Data Archives within African 
universities could counter fears of bias in the data produced $^{47}$. Another advantage of housing these facilities at institutions of higher learning is that African academics, the main users of survey data, could easily access survey microdata. This will also ensure that there is dialogue between these data users and government agencies collecting and supplying the survey data, concerning the requirements for secondary analysis.

\section{Finding Indigenous Solutions}

Wherever they are situated within African countries, Survey Data Archives can play a vital role in regional data sharing for development. Quantitative data from surveys can be used for "problem-solving, policy-oriented research" in Africa, or applied research for solving the development problems in African countries ${ }^{48}$. Re-use of these data can spur creation of indigenous knowledge for growth. Best practices from Survey Data Archives worldwide can be utilised to develop an effective data sharing network in Africa, but one should avoid simply imitating unapplicable practices and trends in creating this research and policy resource.

Existing data support projects funded by international organisations should be examined critically to ensure they suit local requirements. Technological innovations can only provide advantages to African countries where skills are developed and technical resources made available. A third necessity in ensuring innovations are optimized is establishing institutions that connect data producers to data users. The development of a network of African Survey Data Archives on the continent could fulfil this condition, and act as both a catalyst for the production of high-quality statistical data, and a facility for sharing these data for practical use.

* Lynn Woolfrey. Lynn.Woolfrey@uct.ac.za. Lynn Woolfrey is Data Manager at the DataFirst Survey Data Archive, University of Cape Town.

\section{References}

${ }^{1}$ Mwase, N. 1986. Social science research in Eastern and Southern Africa. International Social Science Journal 38(1):145

${ }^{2}$ Personal communication with Professor Robert McCaa, IPUMS International, 2006

${ }^{3}$ Marshalling technology for development: proceedings of a symposium. 1995. Washington: National Academies Press:19, 61-62

${ }^{4}$ [SADA] South African Data Archive website, 2007. [Online]. Available: http://www.nrf.ac.za/sada

\footnotetext{
${ }^{5}$ Musgrave, S. 2003. The metadata dynamic: ensuring
}

data has a long and healthy life. Association for Survey Computing. [Online]. Available: http://www.essex.ac.uk hhs/staff/musgrave/ascmetadata(revised)pdf

${ }^{6}$ Email communication between DataFirst staff and the staff of Statistics South Africa

${ }^{7}$ Kiregvera, B. 2001. Novel statistical capacity building initiatives: Addis Ababa Plan of Action and PARIS21. International Statistical Institute. [Online] Available: http:// isi.cbs.nl: $1-2$

8 [IHSN] The World Bank International Household Survey Network website. [Online]. Available: http://www.internati onalsurveynetwork.org

${ }^{9}$ African Symposium on Statistical Development (ASSD) website, 2007

${ }^{10}$ African charter paves way for professional data crunching across the continent, Article in the Business Report, 21 June, 2007

${ }^{11}$ Lesaoana, M.A. 1997. Data archiving in Africa: the South African experience. IASSIST Quarterly Volume 21 Number 1:4-7

${ }^{12}$ Mudesir Seid, Y. 2004. Implementing a National Data Archive in Ethiopia: Challenges and Experiences. Paper presented at the 2006 IASSIST Conference. May 2006. Ann Arbor, Michigan. [Online]. Available: http://www. iassist.org.

${ }^{13}$ Clubb in Feinberg, E., Martin M..E. and L. M.L. Straf. Eds. 1985. Sharing research data. Washington: National Academies Press.49-50

${ }^{14}$ Boruch in Feinberg, E., Martin M..E. and L. M.L. Straf. Eds. 1985. Sharing research data. Washington: National Academies Press:114

${ }^{15}$ Wilson, F. and Horner, D. 1995. Lessons from the Project for Statistics on Living Standards and Development: the South African story. (Unpublished paper).

${ }^{16}$ DataFirst statistics, 2007

${ }^{17}$ Marshalling technology for development: 31

${ }^{18}$ Hausstein, B. and de Guchteneire, P. 2002. Social Science Data Archives in Eastern Europe: results, potentials and prospects of the archival development. Bergisen Gladbach: E. Ferger Verlag:59

${ }^{19}$ Roma Declaration on Research and Development in Southern Africa, 1981 in Mwase:139 (repeat) 
${ }^{20}$ Mwase: 139

${ }^{21}$ Mwase: 145

${ }^{22}$ Regionalization of social sciences in Latin America, Asia and Africa. 1973. International Social Science Journal 25(4):557:559

${ }^{23}$ Cook in Statistical Confidentiality and access to microdata. Proceedings of the Seminar Session of the 2003 Conference of European Statisticians. 2003. New York: United Nations. [Online]. Available: http://www.eurostat.eu

${ }^{24}$ Hausstein and de Guchteneire:59-60

${ }^{25}$ Bits of power: issues in global access to scientific data. 1997. Washington: National Academies Press:41

${ }^{26}$ ASSD website, 2007

27 Internet World Stats website, 2007 [Online]. Available: http://www.internetworldstats.com

${ }^{28}$ Adam, L. Electronic networking for the research community in Ethiopia in Bridge builders: African experiences with information and communication technology. 1996. Washington: National Academies Press

${ }^{29}$ Bits of power: $41-42$

${ }^{30}$ SADA website, 2007[Online]. Available: http://www.nrf. ac.za/sada and DataFirst website, 2007. [Online]. Available: http://www.datafirst.uct.ac.za

${ }^{31}$ Bits of power: 27

32 [MADIERA] Multilingual Access to Data Infrastructures of the European Research Area website, 2007. [Online]. Available http://www.madiera.net

33 Afrobarometer website, 2007. [Online]. Available: http:// www.afrobarometer.org

${ }^{34}$ Personal communication with Matthew Welch, Director of DataFirst, 2007

${ }^{35}$ Guide to social science data preparation and archiving: best practice throughout the data life cycle. 2005. 3rd edition. Ann Arbor: Inter-university Consortium for Political and Social Research

${ }^{36}$ Cook in Statistical Confidentiality and access to microdata. Proceedings of the Seminar Session of the 2003 Conference of European Statisticians. 2003. New York: United Nations. [Online]. Available: http://www.eurostat. eu: 1
${ }^{37}$ Lane in Statistical Confidentiality and access to microdata. Proceedings of the Seminar Session of the 2003 Conference of European Statisticians. 2003. New York: United Nations. [Online]. Available: http://www.eurostat. eu: 12

${ }^{38}$ Feinberg, E., Martin M..E. and M.L. Straf. Eds. 1985. Sharing research data. Washington: ational Academies

Press:20

${ }^{39}$ Dunne, S. and Austin, E.W. 1998. Protecting confidentiality in archival data resources. ICPSR Bulletin 19(1):1-6

40 Taylor, M. 1994. Ethical considerations in European cross-national research. International Social Science Journal 46(4):523-532.

${ }^{41}$ Bits of power:41-42

${ }^{42}$ Hausstein and de Guchteneire:58

${ }^{43}$ IHSN website

${ }^{44}$ Personal communication with Matthew Welch, Director of DataFirst, 2007

${ }^{45}$ Hausstein and de Guchteneire

${ }^{46}$ Mudesir Seid, 1-5

${ }^{47}$ Lesaoana, M.A. 1997. Data archiving in Africa: the South African experience. IASSIST Quarterly Volume 21 Number 1:6

${ }^{48}$ Mwase: 139 